\title{
A genealogia intersubjetiva da responsabilidade: sensibilidade como locus da epifania em Emmanuel Levinas
}

\section{The intersubjective genealogy of responsibility: sensitivity as epiphany locus in Emmanuel Levinas}

\section{MARÍLIA MENDONÇA DE SOUZA LEÃO SANTOS ${ }^{1}$}

Resumo: O presente ensaio consiste numa breve exegese genealógica da responsabilidade - princípio da heteronomia em que se arraiga a doação ética de sentido - no pensamento filosófico de Emmanuel Levinas. A partir da radicalização da sensibilidade entabulada pelo fenomenólogo francolituano, propomo-nos a demonstrar, inicialmente, a estratificação da subjetividade em Totalidade e Infinito (1961), contemplando seus momentos basilares e distintivos desde o registro pré-objetivo da fruição: a personificação na hipóstase, o envolvimento nas ocupações da existência econômica e, subsequentemente, a relação face a face; encontro com a infinitude enigmática do Outro, que confere ao sujeito uma investidura responsável. Dessa feita, encaminhamo-nos para o assentamento definitivo da subjetividade que, em Outramente que Ser ou Mais-Além da Essência (1974), se verte na própria responsabilidade; imbricada à proximidade e à substituição, dá-se como vulnerabilidade afetiva e experiência imediata da transcendência. Tendo exposto o norte investigativo e as modalizações da subjetividade com vistas à sua concreção como responsabilidade intransponível e inalienável pelo Outro, apontamos para o estatuto originário da sensibilidade na ética metafenomenológica levinasiana. Em oposição à ilogicidade e à minoridade outorgadas pela tradição filosófica

${ }^{1}$ Bacharelanda em Filosofia pela Universidade Federal de Pernambuco (UFPE) selecionada para o programa de mobilidade acadêmica na Universidade de Coimbra (UC). É integrante do Núcleo de Pesquisa e Estudos em Fenomenologia (NUFEPE) - na condição de colaboradora em nível de graduação - e participante do grupo de estudos em torno do pensamento de Martin Heidegger, ofertado pelo Departamento de Filosofia da UFPE e coordenado pelo Prof. Dr. Sandro Márcio Moura de Sena. Tem interesse de pesquisa na área de Filosofia Contemporânea, com ênfase em Fenomenologia-Hermenêutica. 
A genealogia intersubjetiva da responsabilidade: sensibilidade como locus da epifania em Emmanuel Levinas

ocidental, a sensibilidade emerge aí como condição de possibilidade da eticidade e horizonte genético de toda a significação.

Palavras-chave: Sensibilidade. Subjetividade. Responsabilidade.

Abstract: This essay presents, briefly, a genealogical exegesis of responsibility - principle of heteronomy in which the ethical endowment of meaning is rooted - in the philosophical thought of Emmanuel Levinas. Through the radicalization of sensibility undertaken by the FrenchLithuanian phenomenologist, we propose to demonstrate, first, the stratification of subjectivity in Totality and Infinity (1961), contemplating its fundamental moments from the elemental sphere of enjoyment: the personification by hypostasis, the engagement in transactions of economic existence, and, subsequently, face-to-face relationship; encounter with the enigmatic infinity of the Other, who invests the subject with responsibility. Thereafter, we proceed by describing the ultimate formulation of subjectivity, which, in Otherwise than Being or Beyond Essence (1974), is the coming to pass of responsibility itself; imbricated in proximity and substitution, it is the affective vulnerability and the immediate experience of transcendence. Having shown the course of the investigation and the several guises of subjectivity towards its concretion as insurmountable and inalienable responsibility for the Other, we aim to emphasize the overriding status of sensibility in Levinas's metaphenomenological ethics. Opposed to the illogical and minor sense granted by the Western philosophical tradition, the sensibility emerges here as condition of possibility of Ethics and genetic horizon of all significance.

Keywords: Sensibility. Subjectivity. Responsibility.

A sensibilidade se plenifica no alargamento da sua própria amplidão - como rarefação ou desmaio do nosso existir. Nos recônditos do prazer incipiente, algo se abre, tal e qual um precipício, sempre mais e mais abissal, em que a nossa existência, já não resistindo, se regurgita (LEVINAS, 2003, p. 
$61)^{2}$.

O repúdio ao primado da autossuficiência do ser se projeta como leitmotiv da obra filosófica de Emmanuel Levinas - radicada como tarefa de revelar, através da análise fenomenológica da vida concreta, uma relação que escape à aglutinação totalitária perpetrada no engendramento da filosofia ocidental ${ }^{3}$. O pressentimento de uma tal relação - para além dos grilhões da consciência teorética - se manifesta já nos escritos de juventude 4 e se conserva como traço onipresente na constelação do pensamento de Levinas. Nesta perspectiva, seu itinerário pode ser descrito como o amadurecimento assistemático de uma intuição fundamental: a excedência do ser. Com efeito, a recusa à ontologia clássica e a proposta de superação do imperialismo da egologia demarcam a transição entre o período de

2 "It exists wholly in the enlargement of its own amplitude, which is like the rarefaction of our existence [être], or its swooning. In the very depths of incipient pleasure there opens something like abysses, ever deeper, into which our existence, no longer resisting, hurls itself" [Tradução e grifos nossos].

3 Para Levinas, a história da filosofia, de Parmênides a Heidegger, coincide com a história do domínio e da neutralização da alteridade: "A Filosofia ocidental foi, na maioria das vezes, uma Ontologia: uma redução do Outro ao Mesmo, pela intervenção de um termo médio e neutro que assegura a inteligência do ser. [...] Conhecer ontologicamente é surpreender no ente oposto aquilo por que ele não é este ente, este estranho, mas aquilo por que ele se trai de algum modo, se entrega, se abandona ao horizonte em que se perde e aparece, se capta, se torna conceito. Conhecer equivale a captar o ser a partir de nada ou a reduzi-lo a nada, arrebatarlhe a sua alteridade. [...]. No que concerne às coisas, a tarefa da Ontologia consiste em captar o indivíduo (que é o único a existir) não na sua individualidade, mas na sua generalidade (a única de que há ciência). A relação com o Outro só aí se cumpre através de um terceiro, que encontro em mim. $O$ ideal da verdade socrática assenta, portanto, na suficiência essencial do Mesmo, na sua identificação de ipseidade, no seu egoísmo. A Filosofia é uma egologia" [Grifos nossos] (LEVINAS, 1988b, p. 31).

${ }^{4}$ Cf. LEVINAS, 1935; 1947; 1947-8; 1949. 
A genealogia intersubjetiva da responsabilidade: sensibilidade como locus da epifania em Emmanuel Levinas

exegese crítica $^{5}$ das doutrinas de Edmund Husserl e Martin Heidegger e o despontamento de uma filosofia autônoma, cuja trajetória perpassa o exame estrutural da subjetividade - sob a égide da existência, da alteridade e da transcendência - e culmina na arrojada afirmação da Ética como prima philosophia. O uso termo ética aqui, cabe frisar, não remete às modalidades de cunho prescritivista, utilitarista ou deontológico de teorização da moral, conforme adverte Jacques Derrida no ensaio intitulado Violência e Metafísica (1967): "Ética, no sentido levinasiano, é uma Ética sem lei e sem conceito, que mantém sua pureza não-violenta se, e apenas se, precede a determinação dos conceitos e leis"6 (DERRIDA, 2005, p. 120); trata-se de um relacionamento - anterior a qualquer enfoque ontognoseológico e, portanto, indescritível em termos de simetria, reciprocidade ou equidade - em que irrompe a significação do humano: a epifania do infinito. A relação ética - ultrapassagem da quadratura ontológica da totalidade - emerge como ápice do projeto levinasiano que, esteado na reinterpretação da sensibilidade e da afetividade, cinge as guisas do sujeito desde a vivência précompreensiva à defrontação mundana e fatual com Outrem. Destarte, a Fenomenologia7 professada por Levinas se delineia como

\footnotetext{
${ }^{5}$ Cf. LEVINAS, 1930; 1932.

6 "Ethics, in Levinas's sense, is an Ethics without law and without concept, which maintains its non-violent purity only before being determined as concepts and laws.". [Tradução e grifos nossos]. DERRIDA, Jacques. Violence and Metaphysics: an Essay on the Thought of Emmanuel Levinas (KATZ, 2005, p. 120).

7 Atitude investigativa na qual se versou enquanto pupilo de E. Husserl e, mais tarde, de M. Heidegger. Não obstante, balizar a fenomenologia levinasiana como análoga às predecessoras redunda em uma simplificação, visto que a tradição fenomenológica, sendo esteio de incontáveis desdobramentos, não se deixa precisar na qualidade de uma vertente congruente e uniforme. A despeito da
}

Diaphonía, ISSN 2446-7413, v. 2, n. I, 2016 
uma antropologia material da vida subjetiva ou, dita de outro modo, como uma hermenêutica da faticidade inter-humana, que ganha seus contornos decisivos em duas magna opera: Totalité et Infini: Essai sur l'Extériorité (1961) e Autrement Qu'être ou Au-Delà de l'Essence (1974).

O cumprimento do propósito inicial da especulação de Levinas - a ruptura do enclausuramento do ser na síntese universal do conhecimento - exige o abandono do pensamento fixado no objeto, porém, alheio aos processos de subjetivação que condicionam os modos em que a própria objetividade é apreendida. Era isto que provocar uma cegueira da consciência no tocante àquilo que possibilita seu revestimento significativo ${ }^{8}$. O esforço crítico do filósofo de Kaunas inicia com a denúncia do paradigma representativo e analógico da exterioridade - que limita "os indivíduos [...] a portadores de formas" (LEVINAS, 1988b, p. 10) - e logra, paulatinamente, um sentido intersubjetivo enraizado na vida fática. Em rigor, a significação da existência material e concreta é

duradoura influência de seus mestres, E. Levinas se emancipa à medida que se afasta dos seus ditames conceituais para dedicar-se à perquirição ética; articulada, mais tarde, em uma fenomenologia independente ou - tal como batizada por J. Derrida em "Violência e Metafísica" - metafenomenologia. Cf. DERRIDA, 2005, p. 95 .

8 Destacamos, aqui, uma contiguidade patente com a crítica da representação elaborada por Merleau-Ponty, em 1945: "As representações científicas segundo as quais eu sou um momento do mundo são sempre ingênuas e hipócritas, porque elas subentendem, sem mencioná-la, essa outra visão, aquela da consciência, pela qual antes de tudo um mundo se dispõe em torno de mim e começa a existir para mim. Retornar às coisas mesmas é retornar a este mundo anterior ao conhecimento do qual o conhecimento sempre fala, e em relação ao qual toda determinação científica é abstrata, significativa e dependente" [Grifos do autor] (MERLEAU-PONTY, 1999, p. 4). 
A genealogia intersubjetiva da responsabilidade: sensibilidade como locus da epifania em Emmanuel Levinas

irredutível às operações sintéticas da racionalidade: "vivemos de 'boa sopa', de ar, de luz, de espectáculos, de trabalho, de ideias, de sono, etc. Não se trata de objectos de representações" (LEVINAS, 1988b, p. 96). Perfazendo tal crítica, Levinas descobre uma senda para o horizonte primevo da subjetivação na via genética da Fenomenologia, cuja radicalização conduz ao "campo do sentir originário"9 como afetividade pré-objetiva. A via genética - enquanto retorno à experiência dinâmica através da qual se dá a emergência de sentido - se desdobra simultaneamente em uma estesiologia e em uma alterologia ${ }^{10}$ à medida que patenteia a sensibilidade e a aparição do Outro como condições sine qua non de toda significatividade. A análise fenomenológica do sentido é permeada por sínteses que não se resolvem em objetivações e que demandam uma implicação sensual e intersubjetiva do Outro; dessa feita, é no âmago da subjetividade encarnada que a significação se produz. Esta reorientação da subjetividade revela a sua disposição essencial como sensibilidade - sujeição - e a sua origem "na independência e na soberania da fruição" (LEVINAS, 1988b, p. 99). A radicalidade desta assertiva far-se-á clara no esboço da corporeidade; baluarte da reabilitação fenomenológica do sensível.

Embora inspirada na conferência de espessura à sensibilidade intersubjetiva e na tomada do corpo próprio [Leib] como exposição à exterioridade no mundo-da-vida [Lebenswelt], a configuração da subjetividade encarnada extrapola a Fenomenologia de Husserl conservando estritamente seu caráter metodológico - ao passo em que sustém o corpo como "carne e sangue, que não remete às

${ }^{9}$ Cf. CEREZER, 2011, p. 24-49.

${ }^{10}$ Teorias da sensibilidade e da alteridade, respectivamente.

Diaphonía, ISSN 2446-7413, v. 2, n. I, 2016 
estruturas transcendentais idealizáveis e capazes de sustentar [...] relações e percepções, mas um corpo disponível, mais do que corporalidade, corporeidade" (SAYÃO, 2006, p. 157). O estrato préreflexivo e inobjetivo da encarnação sensível preludia um apoderamento de si - "uma maneira de possuir e de trabalhar, de ter tempo, de superar a alteridade daquilo de que eu devo viver" - em que "o $e u$, liberto do mundo pela necessidade, consegue superar a própria miséria da libertação” (LEVINAS, 1988b, p. 102). Corpo, neste prisma, é o grau originário de toda a experiência; para além do aparato meramente orgânico e fisiológico, "é o princípio em direção ao aqui e agora a partir dos quais tudo se produz pela primeira vez" (LEVINAS, 1997, p. 144). A natureza fundamentalmente pathética ${ }^{11}$ do sujeito corpóreo - que não se esgota na egologia do idealismo transcendental husserliano - faculta a abertura de afecções que modalizam sua existência tangível; nomeadamente, a sensibilidade pré-ética - antropogênese pela individuação no dispêndio fruitivo - e a sensibilidade ética ${ }^{12}$ - subjetivação moral e responsável frente à heterogênese. Os registros afetivos alcançados na reinterpretação fenomenológica do corpo trazem à tona os momentos constitutivos da subjetividade no mundo circundante, viabilizando a descrição do seu surgimento e personificação na fruição desinteressada até o seu entrelaçamento traumático com a alteridade no cerne da relação ética. Grosso modo, o trato da dimensão corporal serve à explicitação

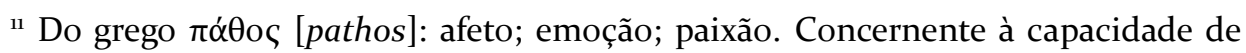
afetar-se. Cf. GOBRY, 2007, p. 22.

12 Salientamos que a explicitação destes registros não implica uma separação sistemática nem tampouco sua sucessão diacrônica; tais afecções são tratadas na perspectiva de uma intriga que as coaduna sem, contudo, dissipar sua autonomia. Cf. CEREZER, 2010, p. 8. 
A genealogia intersubjetiva da responsabilidade: sensibilidade como locus da epifania em Emmanuel Levinas

de que "a subjetividade não é o ego e sim eu mesmo"13 (CRITCHLEY; BERNASCONI, 2004, p. 22); não é o polo de atividade intencional, mas, antes, o próprio indivíduo, em sua singularidade, responsivo e responsável. A conjuntura prioritária que Levinas reivindica para a Ética só se justifica à medida que concerne $a$ mim e não a um ego impessoal, universal e hipotético lançado numa sequência de imperativos possíveis. É somente pela minha experiência avassaladora do Outro - apelo ao qual não posso plenamente atender e do qual jamais poderei escapar - que a Ética adquire uma consistência verdadeiramente positiva.

Motivado pelo projeto heideggeriano ${ }^{14}$ de desvendar o sentido do ser-aí através dos seus modos de ser na cotidianidade mediana [durchschnittliche Alltäglichkeit] e pelo perspicaz arranjo da disposição afetiva [Befindlichkeit] como condição fundamental em que todo ente se arraiga e se encontra, Levinas erige a existência econômica como ponto inaugural da investigação efetuada em Totalidade e Infinito; delineamento genealógico da subjetividade que, por sua vez, desponta na sensibilidade fruitiva: "relação última com a plenitude substancial do ser, com a sua materialidade, a fruição abrange todas as relações com as coisas" (LEVINAS, 1988b, p. 117).

\footnotetext{
13 "As Levinas puts it, 'la subjectivité n'est pas le Moi, mais moi' ('subjectivity is not the Ego, but me')" [Tradução nossa].

${ }^{14}$ Ao ser entrevistado por Philippe Nemo, em 1981, Levinas assinala a tematização da faticidade realizada em Ser e Tempo (1927) como a mais ilustre contribuição de Heidegger ao pensamento filosófico: "O que chamou a minha atenção em 'Sein und Zeit' foi [...] a intencionalidade animando o existir e toda uma série de 'estados de alma' que, antes da fenomenologia heideggeriana, passavam por 'cegos', por simples conteúdos; as páginas sobre a afetividade, sobre a Befindlichkeit e, por exemplo, sobre a angústia, [...] se mostram verdadeiramente significativas" [Grifos nossos] (LEVINAS, 1988a, p. 32).
}

Diaphonía, ISSN 2446-7413, v. 2, n. I, 2016 
Com efeito, a fruição (jouissance) é a guisa elementar da sensibilidade pré-reflexiva, na qual o sujeito se põe diante dos conteúdos de que vive num "fruir sem utilidade, em pura perda, gratuitamente, sem remeter para mais nada, em puro dispêndio" (LEVINAS, 1988b, p. 118); trata-se, pois, de uma ligação primária com o mundo que, de imediato, se oferece como objeto de desejo e desfrute. Neste ínterim, os objetos do desejo fruitivo não remetem a uma preocupação com a existência mas servem à sua própria tessitura, conferindo-lhe um contorno significativo. Entrementes, o desejo - que é, irremediavelmente, desejo de algo - comporta uma separação definitiva entre o desejante e o desejável. É nesta cisão que

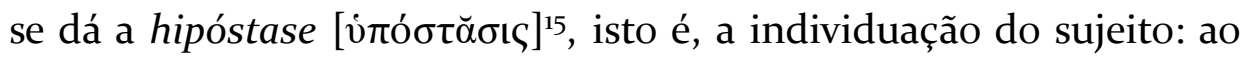
sentir e saciar a fome que perturba seu gozo, o sujeito percebe o alimento como uma ruptura de si mesmo, sobrepondo-se à exterioridade nutritiva e galgando suas propriedades inalienáveis. Este movimento interno se revela como antropogênese: "surgimento de si-mesmo a partir da fruição" (LEVINAS, 1988b, p. 104), que arranca o sujeito da impessoalidade do $\operatorname{ser}^{16}$. Configurado enquanto singularidade destacada da amálgama do mundo, o sujeito vê-se acometido por uma insegurança que provoca o adiamento do seu prazer gratuito; assim, além de sentir-se fartado pelo consumo dos víveres, sente-se ameaçado pela possibilidade da sua falta. Esta ameaça - que suscita um desejo de supressão da necessidade - inverte o egoísmo do mero contentamento para-si reinante na sensibilidade pré-ética ao conduzir o sujeito à relação com Outrem e, por ela, a sua

\footnotetext{
${ }^{15}$ Y $\pi$ $\sigma \tau \alpha \sigma ı \sigma$ [hypóstasis]: substância; pessoa. Cf. GOBRY, 2007, p. 78.

${ }^{16}$ Cf. LEVINAS, 1988b, p. 131: "A fruição é a própria produção de um ser que nasce, que rompe a eternidade tranquila da sua existência seminal ou uterina, para se encerrar numa pessoa, que, vivendo do mundo, vive em sua casa".
} 
A genealogia intersubjetiva da responsabilidade: sensibilidade como locus da epifania em Emmanuel Levinas

ressignificação como responsabilidade.

É por meio do engajamento nas transações da existência econômica - na produção da sua morada e na manutenção de si pelo trabalho - que o sujeito se depara com a exterioridade intransponível do Outro. A acepção levinasiana da alteridade, diametralmente oposta à constituição de Outrem como alter ego ${ }^{17}$, pode ser descrita nos termos de uma enigmologia: em virtude da sua forma ambivalente de "se manifestar sem se manifestar, chamamos-lhe voltando à etimologia desse termo $\operatorname{grego}^{18}$ e por oposição ao aparecimento indiscreto e vitorioso do fenômeno - enigma" (LEVINAS, 1997, p. 254). O Outro é, portanto, um mistério, uma estranheza refratária à representação e resistente aos demais esforços de apoderamento conceitual que, muito embora se insinue como fenômeno, permanece indesvendável em sua conjunção enigmática; fato que o salvaguarda da assimilação na "filosofia digestiva"19. Dessa feita, Levinas concede à relação com este estrangeiro uma investidura metafísica; quista, por seu turno, como disposição afetiva que "tende para uma coisa inteiramente diversa, para o absolutamente outro" (LEVINAS, 1988b, p. 21). Esta afecção - Désir ou Desejo do Infinito que "não assenta em nenhum parentesco prévio" e que "não

${ }^{17}$ Referimo-nos à concepção husserliana da alteridade: "Só poderíamos pensá-lo [o Outro] como algo análogo àquilo que 'me pertence'. Graças à constituição de seu sentido, ele aparece de maneira necessária no meu 'mundo' primordial, na qualidade de modificação intencional do meu eu, a objetividade em primeiro lugar. Do ponto de vista fenomenológico, o outro é uma modificação do 'meu' eu" [Grifos nossos] (HUSSERL, 2001, p. 129).

${ }^{18}$ Aïvır $\mu \alpha$ [aínigma].

19 Sob a égide da Ontologia, o Outro é absorvido pelo Mesmo tal como o alimento; uma "filosofia digestiva", conforme metaforiza Sartre aos neokantianos franceses. Cf. CRITCHLEY; BERNASCONI, 2004, p. 16.

Diaphonía, ISSN 2446-7413, v. 2, n. I, 2016 
poderemos satisfazer" (LEVINAS, 1988b, p. 22) - culmina num intermédio dos registros da sensibilidade, no qual o sujeito, abandonando sua reclusão no deleite fruitivo, adquire um posicionamento pró-ético, isto é, põe-se em trânsito para o Outro. A terminologia evocada para designar tal movimento parece, prima facie, apontar para um estágio em que o existente se encontra encerrado em solus ips. A existência humana, todavia, jamais é solipsista: a personificação da subjetividade encarnada é já concomitante ao impacto proveniente da exterioridade que a circunda. A assimetria radical que separa o sujeito de Outrem é, em última instância, o motivo pelo qual a transição entre os domínios da sensibilidade não se deixa captar enquanto passagem linear a uma etapa estanque que suplanta e elimina a antecedente, mas tão somente como intriga ética. No núcleo desta, dá-se uma gradação ascendente da experiência da exterioridade, demarcada pela distinção ${ }^{20}$ entre autre - aquilo que, à semelhança das janelas e das portas, é outro como conjuntura mundana passível de ser manuseada e usufruída - e Autrui - o metafisicamente Outro ${ }^{21}$, incógnita que emerge como rosto [visage]:

\footnotetext{
${ }^{20}$ Cf. CRITCHLEY; BERNASCONI, 2004, p. 16.

${ }^{21}$ Cf. LEVINAS, 1988b, p. 26: "O Outro metafísico é outro de uma alteridade que não é formal, de uma alteridade que não é um simples inverso da identidade, nem de uma alteridade feita de resistência ao Mesmo, mas de uma alteridade anterior a toda a iniciativa, a todo o imperialismo do Mesmo; outro de uma alteridade que constitui o próprio conteúdo do Outro; outro de uma alteridade que não limita o Mesmo, porque nesse caso o Outro não seria rigorosamente Outro: pela comunidade da fronteira, seria, dentro do sistema, ainda o Mesmo. $\mathrm{O}$ absolutamente Outro é Outrem; não faz número comigo. A colectividade em que eu digo 'tu' ou 'nós' não é um plural de 'eu'. Eu, tu, não são indivíduos de um conceito comum. Nem a posse, nem a unidade do número, nem a unidade do conceito me ligam a outrem".
} 
A genealogia intersubjetiva da responsabilidade: sensibilidade como locus da epifania em Emmanuel Levinas

O modo como o Outro se apresenta, ultrapassando a ideia do Outro em mim, chamamo-lo, de facto, rosto. Esta maneira não consiste em figurar como tema sob o meu olhar, em expor-se como um conjunto de qualidades que formam uma imagem. $\mathrm{O}$ rosto de Outrem destrói em cada instante e ultrapassa a imagem plástica que ele me deixa, a ideia à minha medida e à medida do seu ideatum - a ideia adequada. Não se manifesta por essas qualidades, mas $\kappa \alpha \theta^{\prime} \alpha u \tau^{22}$. Exprime-se. O rosto, contra a Ontologia contemporânea, traz uma noção de verdade que não é o desvendar de um Neutro impessoal, mas uma expressão: o ente atravessa todos os invólucros e generalidades do ser, para expor na sua 'forma' a totalidade do seu 'conteúdo' (LEVINAS, 1988b, p. 37-38).

A palavra francesa visage remonta, etimologicamente, à visão e designa - em consonância com os significados circunscritos nos

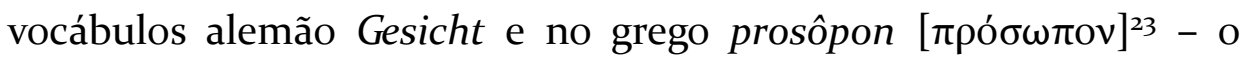
evento de ver e ser visto; seu sentido enfático, todavia, só vem à tona ao passo em que o rosto é compreendido como a autopresença corpórea do Outro; o rosto de Outrem não equivale a uma mera imagem que se nos apresenta, para além da tessitura plástica e da composição de seus elementos visíveis, é o locus em que acontece a acolhida da exterioridade. A alteridade não é nada que se oculte sob a superfície de alguém que ouvimos, vemos, tocamos ou violamos; é o Outro enquanto tal - e não este ou aquele aspecto dele ou dela - que se condensa no rosto ${ }^{24}$. Neste sentido, dirá Levinas, todo e qualquer trato estabelecido com Outrem dá-se nos termos de um embate

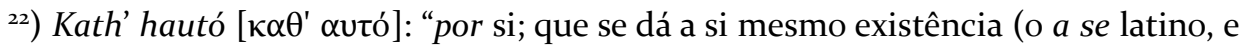
não o per se ou in se = substância: aquilo que existe de si mesmo, e não por seus acidentes).”. In: GOBRY, 2007, p. 36.

23) Literalmente, ato de olhar.

24) Cf. WALDENFELS, 2004, p. 64-66.

Diaphonía, ISSN 2446-7413, v. 2, n. I, 2016 
frente a frente: esta interação "é a única que introduz uma dimensão da transcendência e nos conduz para uma relação totalmente diferente da experiência no sentido sensível do termo, relativa e egoísta" (LEVINAS, 1988b, p. 172). Sendo simultaneamente presença e ausência - visto que se impõe ao sujeito enquanto transcendente e se esquiva da aglutinação promovida pela consciência reflexiva e tematizadora -, o rosto humano instaura a dimensão do divino.

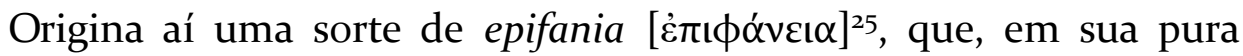
expressão, forma a primeira palavra. Destarte, o Outro é concessor de um sentido que precede a minha doação significativa [Sinngebung]. Consequentemente, ele ensina-me o que, por conta própria, não poderia aprender: aquilo que, sem o proferimento de palavra alguma, me convoca para o que há de implícito em seu apelo. Esta infinitude - sobre a qual eu não posso poder - é, em seu próprio rosto, a expressão original: "não cometerás assassínio" 26 [tu ne commettras pas de meurtre] ou, ainda, "não matarás" [tu ne tueras pas]. A linguagem silenciosa do rosto - "que torna possível e começa todo discurso" (LEVINAS, 1988a, p. 79) - é a condição fundamental para que a relação entre a subjetividade e a alteridade irrompa; pelo vigor da sua interpelação, o Outro se desvencilha da totalidade decifrável e compreensível, mostrando-se, antes do mais, como alguém a quem eu devo responder. Sou eu - e somente eu - quem pode atender à injunção do seu rosto e, quer a ignore quer não, a obrigação de retorno é intransferível e incontornável; "a epifania do rosto como rosto abre a humanidade” (LEVINAS, 1988b, p. 190).

Intimado a responder à interpelação silenciosa do rosto do

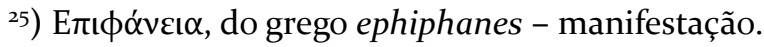

${ }^{26}$ Cf. LEVINAS, 1988b, p. 178.
} 
A genealogia intersubjetiva da responsabilidade: sensibilidade como locus da epifania em Emmanuel Levinas

próximo, o sujeito, outrora dedicado à sua pura fruição, adquire uma investidura responsável que o configura como subjetividade ética. A responsabilidade - concebida como princípio da heteronomia na medida em que investe o indivíduo de responsividade e de liberdade - não é um mero atributo do sujeito racional nem tampouco um fruto da reciprocidade numa relação entre ego e alter ego, mas, sim, um traço inerente e constitutivo da subjetividade como sensibilidade. Precedendo as deliberações do sujeito e a própria consciência do dever, a responsabilidade nos lança ao encargo daqueles que, inesperadamente, nos vêm ao encontro. Isto é: no impacto proveniente do contato com o sagrado encarnado na alteridade, a subjetividade expõe a sua interioridade a fim de acolher a debilidade do Outro e, neste ínterim, galga o conteúdo que a figura como subjetividade ética:

Somos humanos porque somos carne transida pela responsabilidade, capaz de responder responsavelmente ao Outro antes de qualquer pergunta, antes mesmo da efervescência do próprio fenômeno da presença da alteridade, ou seja, somos erigidos desde um contexto de significação sensível que nos lança para fora antes de para-si (SAYÃO, 2006, p. 211-212).

O que está em jogo na concepção levinasiana de Ética começa, enfim, a vir às claras: distante do caráter normativo predominante no discurso filosófico ocidental, aqui chama-se Ética a "impugnação da minha espontaneidade pela presença de Outrem. A estranheza de Outrem - a sua irredutibilidade a Mim, aos meus pensamentos e às minhas posses - realiza-se precisamente como um pôr em questão da minha espontaneidade, como Ética" (LEVINAS, 1988b, p. 30). Esta designa, portanto, o encontro avassalador com a face da alteridade, 
que apela e interdita a vivência costumeira do Eu arraigado no mundo. Disso se depreende que o sujeito não é apenas uma entidade afetada pela mundanidade que então retorna à consciência de si para representar a realidade; ao revés, dado que se constitui fundamentalmente como sensibilidade encarnada - e daí a sua possibilidade de ser para o Outro - é na relação face a face que se dá a passagem para a sua condição propriamente humana. A raiz estrutural da experiência subjetiva é a responsabilidade, cujo sentido precípuo não é outro senão respeitar a alteridade em sua diferença, sem, contudo, ser-lhe indiferente. Ética, isenta de qualquer conteúdo moral, remete ao reconhecimento da transcendência da alteridade e à concessão de sua inexorável separação.

Ao passo em que a alteridade ética no cerne da relação face a face se apresenta como temática privilegiada em Totalidade e Infinito, o ponto nelvrágico da segunda magnum opus levinasiana consiste, em contrapartida, na subjetividade ética e na subsequente descrição de sua estrutura como disposição e sujeição moral ao Outro e para o Outro. Atormentado pelas críticas proferidas por Derrida em Violência e Metafísica - particularmente pela explicitação de que sua tentativa de escapar da Ontologia é ainda refém da linguagem ontológica -, Levinas busca, em Outramente que Ser ou Mais-Além da Essência, expressar a afetividade em seu âmago, valendo-se, para tal, de uma linguagem metafenomenológica e de uma conceitualização minimalista. Ademais, pode-se aventar algumas divergências basilares entre ambas as obras. Dentre elas, destacamos o trato da sensibilidade que, em Totalidade e Infinito, é predominantemente quista sob o registro da fruição necessária à separação e à garantia da transcendência. E, em Outramente que Ser, é balizada a partir do registro da vulnerabilidade [vulnérabilité] - 
A genealogia intersubjetiva da responsabilidade: sensibilidade como locus da epifania em Emmanuel Levinas

somente esboçado na parte final do tratado anterior - enquanto suscetibilidade passiva que aproxima os sujeitos e reverte o egoísmo fruitivo. $\mathrm{O}$ contato travado com a alteridade passará a ser delineado nos termos da proximidade e a epifania do rosto, antes tomada no tocante de uma presença diante de, será abordada nos termos de uma passagem ao Outro na substituição. Trata-se, grosso modo, da tentativa de exceder o âmbito da relação ética para adentrar na subjetivação ética do sujeito encarnado ${ }^{27}$. A despeito dos notórios redirecionamentos apresentados em Outramente que Ser, seria um equívoco se se considerasse que há um retrocesso em relação à espessura conferida à alteridade e ao estatuto prioritário da Ética em Totalidade e Infinito; ao revés, as noções inseridas no último escrito apresentam o processo de maturação do pensamento levinasiano como uma radicalização das perquirições anteriores, que ganham, então, um assentamento definitivo. Em Outramente que Ser e nos escritos subsequentes, a sensibilidade - que desempenhava um papel crucial já em Totalidade e Infinito - remontará à densidade da carne; a responsabilidade será enfatizada como condição de possibilidade de toda a significação e a subjetividade se verterá, enfim, na própria responsabilidade.

O acabamento decisivo da acepção levinasiana de subjetividade se alicerça na reinterpretação da sensibilidade como fruição desinteressada e no seu posterior emparelhamento com uma afecção traumática, articulada a partir do registro sensível da vulnerabilidade como exposição radical à alteridade. Se, em Totalidade e Infinito, o sujeito galga sua separação ao ser acometido pelo desejo de supressão

${ }^{27}$ Cf. LEVINAS, 2012, p. 158.

Diaphonía, ISSN 2446-7413, v. 2, n. I, 2016 
da necessidade que interrompe seu livre gozo, em Outramente que Ser, por sua vez, Levinas apresenta a condição vulnerável como a ruptura autêntica do ensimesmamento egoísta do sujeito que frui. Não obstante, a tematização da vulnerabilidade como configuração intrínseca da subjetividade não implica a exclusão da fruição enquanto modo primevo de lida com a mundanidade, mas, sim, aponta para o deslocamento da enfâse no indivíduo encarnado no mundo para a alteridade; à fruição como traço basilar da sensibilidade será, então, somado o sofrimento do embate traumático com Outrem:

Vulnerabilidade, exposição ao ultraje e à ferida: uma passividade mais passiva que toda paciência, passividade do acusativo, traumatismo da acusação sofrida por um refém até a perseguição, questionamento no refém da identidade que se substitui pelos outros. Si mesmo: deserção ou derrota da identidade do Eu. Eis aqui levada a seu termo a sensibilidade. Isto significa sensibilidade como subjetividade do sujeito: substituição do outro (um em lugar do outro), expiação (LEVINAS, 2012, p. 177).

O advento da vulnerabilidade visa à remissão da subjetividade a um estágio anterior e para além do ser e descobre, na imediatez da proximidade inter-humana, o vestígio da transcendência, que não se encerra na exterioridade manual aberta pelo gozo da fruição e nem na alteridade puramente formal ${ }^{28}$. A análise da subjetividade como vulnerabilidade traz à tona o caráter ambivalente da sensibilidade que, sendo prazer fruitivo, é, concomitantemente, sujeição e abertura às intempéries da exterioridade. Com efeito, a passagem

${ }^{28}$ Cf. CEREZER, 2010, p. 8. 
A genealogia intersubjetiva da responsabilidade: sensibilidade como locus da epifania em Emmanuel Levinas

definitiva para a heterogenia não poderia ser rigorosamente efetuada pelo desejo estrito de saciar a necessidade - dado que, uma vez sanada a carência, poderia o sujeito abandonar-se à animalidade da fruição que se compraz em si mesma -, mas tão somente pelo trauma proveniente da proximidade do Outro. Em função disso, uma vez exposta à alteridade desde sua corporeidade - condição da presteza e da vulnerabilidade eis que "somente um sujeito que come pode ser para o Outro"29 (LEVINAS, 2011, p. 74) - e afetivamente disposta em compadecimento e responsividade, a subjetividade se destaca como refém de uma responsabilidade infinita que antecede toda a liberdade e se inscreve em sua carne. A investidura responsável que está em jogo na relação ética, outrora adquirida em virtude da presença de Outrem, é agora concebida como guisa elementar do sujeito vulnerável, abalado pela alteridade antes até de defrontar-se, efetivamente, com ela.

A compreensão devida da recondução da subjetividade como responsabilidade demanda, além da tomada da vulnerabilidade como grau precípuo de toda vivência corpórea, uma exploração das noções com as quais esta se imbrica, a saber, a proximidade e a substituição. O desdobramento destas noções, cabe reiterar, não remete a uma ordenação sucessiva de etapas da situação ética - a partir das quais o sujeito miraculosamente se faria responsável -, mas, sim, aos distintos níveis do encontro com Outrem. A experiência da alteridade é predicada como proximidade irredutível ao Ser e às operações sintéticas da consciência. Tal experiência é

${ }^{29}$ Only a subject that eats can be for-the-other, or can signify. Signification, theone-for-the-other, has meaning only among beings of flesh and blood" [Tradução nossa].

Diaphonía, ISSN 2446-7413, v. 2, n. I, 2016 
concebida como impossibilidade de permanecer indiferente à interpelação exigente do rosto. A proximidade não é dita daquilo que está ao alcance das mãos ou dos olhos e sim do posicionamento do sujeito, desde sempre convocado à responsabilidade, nos termos de uma deposição de si que o constitui para o Outro:

A proximidade não se resolve na consciência que um ser adquiriria de outro ser que julgasse próximo na medida em que este se encontrasse à sua vista ou ao seu alcance ou na medida em que lhe fosse possível captá-lo, possuí-lo ou entreter-se com ele na reciprocidade dos apertos de mãos, das carícias, da peleja, da colaboração, do comércio ou da conversação. [...] Reunida no Mesmo, congregada na experiência, como por efeito de uma síntese qualquer da multiplicidade, a proximidade já falseou sua extraordinária ambiguidade de um todo rompido pela diferença entre termos, na qual a diferença é não-indiferença e a ruptura, uma obsessão (LEVINAS, 2011, p. $83)^{30}$.

Descrito como "pura aproximação e proximidade, irredutível à experiência da proximidade” (LEVINAS, 1997, p. 277), o embate com Outrem - e o seu avizinhamento sempre iminente - provoca um impacto na subjetividade que, cercada pela obrigação infinita da responsividade, adentra numa obsessão. Esta delineia-se como uma

\footnotetext{
30 "Proximity does not resolve into the consciousness a being would have of another being that it would judge to be near inasmuch as the other would be under one's eyes or within one's reach, and inasmuch as it would be possible for one to take hold of that being, hold on to it or converse with it, in the reciprocity of handshakes, caresses, struggle, collaboration, commerce, conversation. [...] United in the same, assembled into experience, like an effect of any synthesis of multiplicity, proximity has already falsified its extraordinary ambiguity of being a whole broken up by the difference between terms, in which difference is nonindifference and the break is an obsession" [Tradução nossa].
} 
A genealogia intersubjetiva da responsabilidade: sensibilidade como locus da epifania em Emmanuel Levinas

ruptura do interesse da consciência, que produz "um arrancamento de si em prol do Outro na doação do pão tirado da própria boca"31 (LEVINAS, 2011, p. 142). A responsabilidade, em última instância, irrompe na obsessão que incorpora e ressignifica a singularização do sujeito na fruição. A obsessão como o despontar da subjetivação ética aclara - na medida em que se dá como conjuntura insuperável - o fato de que a responsabilidade não se deixa precisar nos termos de um atributo contingente, mas tão somente como a constituição mesma da eticidade subjetiva desvelada na proximidade do próximo. Assim sendo, a origem do sujeito responsável remonta à obsessão como afecção na qual a subjetividade se arranca do ser pela responsabilidade que a constitui e cujo sentido é a substituição. Fadada a suster o peso do padecimento dos que vêm ao encontro na proximidade, a subjetividade percebe, em seu si, uma ordem para além de si. Essa ordem expõe sua interioridade de refém ao ponto da sua conversão em um Outro, apresentando-se no acusativo eis me aqui - presteza e expiação. Em linhas largas, a subjetividade encarnada é a vulnerabilidade que se torna, desde a afecção obsessiva, substituição do Um-para-o-Outro; na aproximação corpórea de Outrem - em si mesma dotada de significação - dá-se a experiência direta da transcendência e a subjetivação ética do sujeito que se desarraiga da essência, da quidditas do ser, para significar outramente.

\section{Considerações finais}

Nosso breve esforço propedêutico teve por meta a descrição da

${ }^{31}$ "It is a being torn up from oneself for another in the giving to the other of the bread out of one's own mouth" [Tradução nossa].

Diaphonía, ISSN 2446-7413, v. 2, n. I, 2016 
responsabilidade desde a genealogia intersubjetiva do sujeito afetivo. Neste percurso, à guisa elementar da subjetividade revelou-se como sensibilidade fruitiva e - através do posterior crivo da linguagem ética - vulnerável. Na proximidade galgada pela análise da sensibilidade enquanto vulnerabilidade, a subjetividade veio à luz como responsabilidade e expiação infinitas na substituição do Si pelo Outro. A tessitura deste caminho expositivo - muito embora não faça a devida justiça à agudez e à minúcia especulativa do pensamento levinasiano - serviu à explicitação de que somente em vista da alteridade encarnada pode a subjetividade individuar-se e configurar-se como eticidade responsável. Daí o estatuto de prima philosophia que Levinas confere à Ética. Uma série de decorrências pode ser aventada a partir das reflexões que fundamentam esta tese tão audaz. Dentre elas, salta aos olhos o alicerce mesmo da ética metafenomenológica formulada por Levinas: a sensibilidade como configuração instituidora da subjetividade. Visto que a relação ética escapa aos ditames da intelecção e resiste às diversas formas de apreensão conceitual, não fosse $o$ registro da sensibilidade radicalizada como vulnerabilidade e abertura imediata à transcendência, a experiência da alteridade enigmática estaria, de todo, interditada. Na medida em que mesmo a linguagem remonte à significação circunscrita na carne, a vulnerabilidade sensitiva se deixa captar enquanto locus de onde emerge o significado. $\mathrm{O}$ paradigma da sensibilidade é, pois, uma conjuntura necessária para o acontecimento do contato que se afigura como linguagem condutora às profundezas do indizível do rosto. A sensibilidade, em última instância, é não somente o como [Wie] da relação ética, mas sua condição de possibilidade - é o seu horizonte de acontecimento. Por meio do exposto, poder-se-ia imputar à fenomenologia levinasiana a 
A genealogia intersubjetiva da responsabilidade: sensibilidade como locus da epifania em Emmanuel Levinas

inversão da ideia onipresente na história da filosofia ocidental, a saber, a tomada da racionalidade como aspecto privilegiado da existência humana e da sensibilidade como traço subsidiário e ludibriante. A existência, antes de qualquer operação cognoscitiva, é abertura ao afetar-se pelo Outro; o ego cogito ergo sum verte-se, aí, em ego sentio ergo sum. A própria Filosofia que, segundo Aristóteles, devém de um espanto maravilhado diante do que há, talvez não encontre sua perplexidade na contemplação do céu estrelado, mas no vislumbre dos olhos do Outro - onde reside uma infinitude palpável, cujo enigma jamais se exaure.

\section{Referências bibliográficas}

BERGO, B. "Emmanuel Levinas". In: The Stanford Encyclopedia of Philosophy. Edição de Primavera, [s. l], 2014. Disponível em: http://plato.stanford.edu/archives/spr2014/entries/levinas/ Acesso em: 01/o6/2014.

BLOECHL, J. (Org.). The face of the other and the trace of God: essays on the philosophy of Emmanuel Levinas. New York: Fordham University Press, 2000.

CEREZER, C. "A dor da responsabilidade: sensibilidade e individuação éticos em Levinas”. In: Kínesis, Santa Maria, RS, vol. 2, n 03, 2010, p. 1-12. Disponível em:

http://www.marilia.unesp.br/Home/RevistasEletronicas/Kinesis/1_C ristianoCereser.pdf

Acesso em: 01/o6/2014.

. Da carne sensível à singularidade ética: a sensibilidade como condição-gênese da individuação na fenomenologia levinasiana. 2011, 185f. Dissertação de Mestrado em Filosofia - UFSM, Santa Maria, 2011. Disponível em: http://w3.ufsm.br/ppgf/menuesp2/467d6ffi85b58boa6d16cadio4db 
d3d5.pdf

Acesso em: 01/06/2014.

CRITCHLEY, S; BERNASCONI, R. (Orgs.). The Cambridge Companion to Levinas. Cambridge: Cambridge University Press, 2004.

DERRIDA, J. "Violence and metaphysics: an essay on the thought of Emmanuel Levinas". In: KATZ, C. E. (Org.). Emmanuel Levinas: critical assessments of leading philosophers. Vol. o1: Levinas, Phenomenology and His Critics. New York: Routledge, p. 88-173, 2005.

GOBRY, I. Vocabulário grego da filosofia. Tradução de Ivone Benedetti. São Paulo: Martins Fontes, 2007.

HUSSERL, E. Meditações cartesianas: introdução à fenomenologia. Tradução de Frank de Oliveira. São Paulo: Madras, 2001.

KATZ, C. E. (Org.). Emmanuel Levinas: critical assessments of leading philosophers. Vol. o1: Levinas, Phenomenology and His Critics. New York: Routledge, 2005.

LEVINAS, E. Collected philosophical papers. Tradução de Alphonso Lingis. Dordrecht: Martinus Nijhoff Publishers, $1987 \mathrm{a}$.

. Descobrindo a existência com Husserl e Heidegger. Tradução de Fernanda Oliveira. Lisboa: Instituto Piaget, 1997.

. Ética e Infinito: Diálogos com Philippe Nemo. Tradução de João Gama. Lisboa: Edições 70, 1988a.

. On escape. Tradução de Bettina Bergo. California: Stanford University Press, 2003.

. Otherwise than being or beyond essence. Tradução de Alphonso Lingis. 9aㅡ ed. Pittsburgh: Duquesne University Press, 2011. . "Outramente que ser ou mais-além da essência: o argumento". Tradução de Cristiano Cerezer. In: Thaumazein, Santa Maria, RS, 
A genealogia intersubjetiva da responsabilidade: sensibilidade como locus da epifania em Emmanuel Levinas

Vol. 5, no 10, p. 156-186, 2012. Disponível em:

http://sites.unifra.br/Portals/1/Numero1o/Cerezer_12.pdf Acesso em: 01/06/2014.

. The Levinas Reader. Seleção e Introdução de Seán Hand.

Oxford: Basil Blackwell, 1989.

. Time and the other and additional essays. Tradução de

Richard Cohen. Pittsburgh: Duquesne University Press, 1987b.

. Totalidade e Infinito. Tradução de José Pinto Ribeiro. Lisboa:

Edições 70, 1988b.

MERLEAU-PONTY, M. Fenomenologia da percepção. Tradução de Carlos Alberto Ribeiro de Moura. $2^{\mathbf{a}}$ ed. São Paulo: Martins Fontes, 1999.

SAYÃO, S. C. "Levinas e o argumento do infinito: um diálogo com

Descartes”. In: Princípios, Natal, vol. 18, nº 30, 2011, p. 143-162.

Disponível em:

http://www.periodicos.ufrn.br/principios/article/view/1718 Acesso em: 01/o6/2014.

. Sobre a leveza do humano: um diálogo com Heidegger, Sartre

e Levinas. Porto Alegre, PUCRS, 2006, 265p [Tese de Doutorado em Filosofia] Disponível em:

http://tede.pucrs.br/tde_busca/arquivo.php?codArquivo=202

Acesso em: 01/o6/2014.

WALDENFELS, B. "Levinas and the face of the other". In:

CRITCHLEY, S; BERNASCONI, R. (Orgs.). The Cambridge

Companion to Levinas. Cambridge: Cambridge University Press, p. 63-81, 2004.

Submissão: 19.02.2016 / Aceite: 10.03.2016

Diaphonía, ISSN 2446-7413, v. 2, n. I, 2016 